\title{
Albert Einstein Cancer Center
}

National Cancer Institute

\section{Source}

National Cancer Institute. Albert Einstein Cancer Center. NCI Thesaurus. Code C39305.

The goal of the Albert Einstein Cancer Center is to foster basic, clinical, population- based, and translational research in an effort to understand better the origins of cancer and its effective prevention, diagnosis, and treatment. It is affiliated with Albert Einstein College of Medicine, and became an NCl-designated Cancer Center in 1992. 